\title{
Pharmacologic disruption of Polycomb-repressive complex 2-mediated gene repression selectively induces apoptosis in cancer cells
}

\author{
Jing Tan, ${ }^{1,7}$ Xiaojing Yang, ${ }^{1,5,7}$ Li Zhuang, ${ }^{1}$ Xia Jiang, ${ }^{1}$ Wei Chen, ${ }^{6}$ Puay Leng Lee, ${ }^{1}$ \\ R.K. Murthy Karuturi, ${ }^{4}$ Patrick Boon Ooi Tan, ${ }^{3,6}$ Edison T. Liu, ${ }^{2}$ and Qiang $\mathbf{Y u}^{1,8}$ \\ ${ }^{1}$ Molecular Pharmacology, Genome Institute of Singapore, 138672, Singapore; ${ }^{2}$ Cancer Biology, Genome Institute of \\ Singapore, 138672, Singapore; ${ }^{3}$ Cell and Medical Biology, Genome Institute of Singapore, 138672, Singapore; ${ }^{4}$ Information \\ and Mathematic Sciences, Genome Institute of Singapore, 138672, Singapore; ${ }^{5}$ Institute of Medicinal Biotechnology, \\ Chinese Academy of Medical Sciences, Beijing 100094, China; ${ }^{6}$ Duke-NUS Graduate Medical School, 169547, Singapore
}

Polycomb-repressive complex 2 (PRC2)-mediated histone methylation plays an important role in aberrant cancer gene silencing and is a potential target for cancer therapy. Here we show that S-adenosylhomocysteine hydrolase inhibitor 3-Deazaneplanocin A (DZNep) induces efficient apoptotic cell death in cancer cells but not in normal cells. We found that DZNep effectively depleted cellular levels of PRC2 components EZH2, SUZ12, and EED and inhibited associated histone H3 Lys 27 methylation (but not H3 Lys 9 methylation). By integrating RNA interference (RNAi), genome-wide expression analysis, and chromatin immunoprecipitation (ChIP) studies, we have identified a prominent set of genes selectively repressed by PRC2 in breast cancer that can be reactivated by DZNep. We further demonstrate that the preferential reactivation of a set of these genes by DZNep, including a novel apoptosis affector, $F B X O 32$, contributes to DZNep-induced apoptosis in breast cancer cells. Our results demonstrate the unique feature of DZNep as a novel chromatin remodeling compound and suggest that pharmacologic reversal of PRC2-mediated gene repression by DZNep may constitute a novel approach for cancer therapy.

[Keywords: EZH2; PRC2; apoptosis; breast cancer; histone methylation]

Supplemental material is available at http://www.genesdev.org.

Received December 19, 2006; revised version accepted March 12, 2007.

Epigenetic alterations play important roles in cancer development. These alterations include both DNA hypermethylation and chromatin modifications such as histone methylation and deacetylation (Jones and Baylin 2002; Feinberg and Tycko 2004; Fraga et al. 2005; Baylin and Ohm 2006). Many tumor suppressors have been found to be inactivated by epigenetic silencing, providing cancer cells with selective advantages for clonal expansion and growth (Baylin and Ohm 2006). Unlike genes harboring disabling genetic mutations, epigenetically silenced tumor suppressor genes can be reactivated to cause cells to go into apoptosis or senescence. This feature makes epigenetic modifications ideal targets for therapeutic interventions in cancer. Therapeutic agents

\footnotetext{
${ }^{7}$ These authors contributed equally to this work.

${ }^{8}$ Corresponding author.

E-MAIL yuq@gis.a-star.edu.sg; FAX 65-6478-9003.

Article published online ahead of print. Article and publication date are

online at http://www.genesdev.org/cgi/doi/10.1101/gad.1524107.
}

aimed at reactivating silenced genes include DNA demethylating agents 5-Azacytidine and its deoxy analog 5-Aza-2'-deoxycytidine (5-AzaC), as well as histone deacetylase inhibitors (HDACI) (Marks et al. 2004; Nebbioso et al. 2005; Yoo and Jones 2006). It has been shown that the specific inhibitors of DNA methylation, 5-Azacytidine and its deoxy analog 5-AzaC, can inhibit DNAdependent methyltransferase (DNMT) activity and reverse the repression of tumor suppressor genes. This therapy has been used to treat hematological malignancies (Jones and Baylin 2002). Clinical trials are also underway for agents that interfere with enzymes that modify histones, such as HDACI (Marks et al. 2004; Nebbioso et al. 2005).

Polycomb group (PcG) proteins are known to have the ability to promote gene repression through epigenetic modification of chromatin structure (Kennison 1995; Levine et al. 2004; Lund and van Lohuizen 2004; Pirrotta 2006). PcGs are highly conserved from Drosophila to human (Kennison 1995; Pirrotta 1999; Kennison 2004) and 
form multiple Polycomb-repressive complexes (PRCs). PRCs contain intrinsic histone methyltransferase (HMTase) activity and maintain gene repression through methylation of core histones (Beisel et al. 2002; Cao et al. 2002; Milne et al. 2002; Muller et al. 2002; Nakamura et al. 2002). Among PcG proteins, PRC2 is of particular importance since it has been linked to stem cell biology and cancer (Kleer et al. 2003; Gil et al. 2005; Bernstein et al. 2006; Boyer et al. 2006; Bracken et al. 2006; Holden 2006; Kalantry et al. 2006; Kamminga et al. 2006; Lee et al. 2006). PRC2 contains three core components: EZH2, SUZ12, and EED (Levine et al. 2004; Kuzmichev et al. 2005). EZH2 contains the HMTase activity, and SUZ12 and EED are required for this activity (Cao and Zhang 2004; Pasini et al. 2004; Montgomery et al. 2005). EZH2 catalyzes histone H3 Lys 27 (H3-K27) methylation and is required for PRC2-mediated gene repression (Cao et al. 2002; Muller et al. 2002; Kirmizis et al. 2004; Kuzmichev et al. 2005).

Human EZH2 (and its associated H3-K27 methyltransferase [MTase] activity) has been linked to cancer. It is overexpressed in metastatic prostate and breast cancer (Sellers and Loda 2002; Varambally et al. 2002; Bracken et al. 2003; Kleer et al. 2003; Rhodes et al. 2003) and has been associated with breast cancer aggressiveness (Kleer et al. 2003). In addition to EZH2, SUZ12 is also up-regulated in several human tumors including those of the colon, breast, and liver (Kirmizis et al. 2003, 2004). In cultured cells, EZH2 was found to be essential for cell proliferation, and overexpression of EZH2 promoted cell transformation (Varambally et al. 2002; Bracken et al. 2003). Thus, as a potential repressor of tumor suppressor genes, the PRC2 complex appears to be an attractive target for therapeutic intervention. However, the mechanism whereby the PRC2 complex promotes tumor progression has not been clearly determined, in part because little is known about the PRC2 target genes specifically repressed in cancer cells. In addition, no drug has been found thus far to perturb PRC2-mediated gene silencing for potential cancer epigenetic therapy.

3-Deazaadenosine analogs are potent inhibitors of Sadenosylhomocysteine (AdoHcy) hydrolase (Chiang and Cantoni 1979; Liu et al. 1992). Inhibition of AdoHcy hydrolase results in the cellular accumulation of AdoHcy, which in turn causes by-product inhibition of S-adonosyl-L-methionine-dependent MTases (Chiang and Cantoni 1979). Although a variety of biological effects have been observed for the 3-deaza nucleosides (Chiang 1981; Razin et al. 1988; Chiang et al. 1992), its effects on chromatin modifications and global gene expression have not been explored. In this study, we found that 3-Deazaneplanocin A (DZNep), one of the most potent AdoHcy hydrolase inhibitors (Glazer et al. 1986), can induce robust apoptosis in cancer cells but not in normal cells. Importantly, DZNep appears to be a unique chromatin remodeling compound that can deplete the cellular PRC2 proteins and inhibit the associated histone methylation. We demonstrate that reactivation of PRC2-repressed genes contributes to DZNep-induced apoptosis in breast cancer cells.

\section{Results}

DZNep induces apoptotic cell death in cancer cells but not in normal cells

We have shown previously that HDAC inhibitors promote E2F1-dependent apoptosis (Zhao et al. 2005; Tan et al. 2006). In an effort to find other HDACI-like compounds, we screened a National Cancer Institute library consisting of nearly 4000 compounds. From this we identified a small-molecule compound, NSC 617989, as a strong activator of oncogene E2F1-mediated apoptosis in our cellular system (X. Yang, J. Tan, and Q. Yu, unpubl.). This compound, DZNep (Fig. 1A), is a known inhibitor of AdoHcy hydrolase (Glazer et al. 1986). We found that DZNep at $5 \mu \mathrm{M}$ induced time-dependent cell death in breast cancer MCF-7 and colorectal cancer HCT116 cells, as determined by propidium iodide (PI) staining and flow cytometry analysis (Fig. 1B). We further demonstrated that DZNep-induced cell death proceeds through apoptosis. Figure 1C shows that DZNep treatment of MCF-7 and HCT116 cells induces marked loss of mitochondrial transmembrane potential (MTP) $(\Delta \Psi \mathrm{m})$, which is an indicator of mitochondrial dysfunction. Furthermore, cleavage of poly (ADP-ribose) polymerase (PARP), a caspase 3 substrate, was easily detectable in DZNep-treated cells (Fig. 1D). These results suggest that DZNep triggers apoptotic cell death involving mitochondria dysfunction and caspase activation.

We next extended our analysis to other types of cancer cells and investigated whether DZNep would induce cell death in normal cells. As expected, DZNep at $5 \mu \mathrm{M}$ also induced cell death in a variety of other cancer cell lines, including breast cancer MB-468 cells, colorectal cancer, RKO, SW480, hepatoma Hep3B, and prostate cancer DU145 cells (Fig. 1E). In contrast, DZNep did not induce obvious cell death in normal cells, including noncancerous breast epithelial MCF-10A cells, lung epithelial IMR90 cells, primary human lung fibroblast cells MRC5 , and human skin fibroblast cells T-HFF. Therefore, DZNep appeared to preferentially induce apoptosis in cancer cells.

\section{DZNep depletes PRC2 proteins and inhibits histone H3-K27 methylation}

We next investigated the molecular mechanism of DZNep-induced apoptosis in cancer cells. Because DZNep produced a similar phenotype as that caused by HDACI in our cellular screening and PRC2-mediated gene repression depends on HDAC activity (van der Vlag and Otte 1999; Varambally et al. 2002), we explored the possibility that DNZep might interfere with PRC2 proteins and related histone methylations.

As shown by Western blot analysis (Fig. 2A), treatment of MCF-7 or HCT116 cells with $5 \mu \mathrm{M}$ DZNep for 48 and $72 \mathrm{~h}$ resulted in the dramatic decrease in protein levels of the three PRC2 components: SUZ12, EZH2, and EED. In agreement with the previous findings that $\mathrm{H} 3-\mathrm{K} 27$ is a specific substrate of PRC2 HMTase (Cao et al. 2002), 
Tan et al.

A

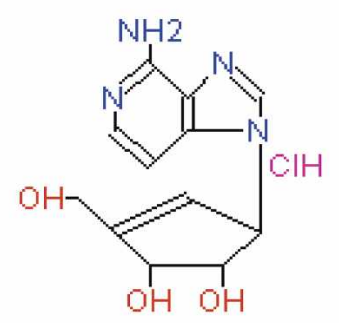

3-Deazaneplanocin A

C

Figure 1. DZNep preferentially induces apoptosis in cancer cells. (A) Chemical structure of DZNep. (B) MCF-7 and HCT116 cells were treated with $5 \mu \mathrm{M}$ DZNep for 48 and 72 $\mathrm{h}$, followed by PI staining and FACS analysis. (C) MCF-7 and HCT116 cells were treated with DZNep for $72 \mathrm{~h}$, followed by JC-1 staining and FACS analysis. MTP was quantified by the cells with lower membrane potential $(\Delta \Psi \mathrm{m})$. (D) MCF-7 and HCT16 cells were treated with $5 \mu \mathrm{M}$ DZNep for 48 and $72 \mathrm{~h}$, and whole-cell extracts were analyzed by Western blotting. Cleavage of PARP was detected after DZNep treatment. $\beta$-Actin was used as a loading control. $(E)$ Cell death response of a variety of cancer cells and normal cells to DZNep. Indicated cells were treated with 5 uM DZNep for up to $120 \mathrm{~h}$ and the cell death was measured by PI staining and FACS analysis. Data represent \pm SD from three independent experiments.

trimethylation of histone 3 at Lys 27 (H3-K27me3) was strongly reduced in DZNep-treated cells. In contrast, histone $\mathrm{H} 3$ trimethylation at Lys 9 (H3-K9me3) - which is mediated by another histone MTase, Suv39h1 (Rea et al. 2000; Peters et al. 2001; Lehnertz et al. 2003)-was not affected by DZNep treatment. In addition, DZNep treatment did not affect histone $\mathrm{H} 3$ acetylation. The expression level of the DNA MTases, known to be depleted upon DNMT inhibitor treatment (Velicescu et al. 2002; Cheng et al. 2004), remained unchanged with DZNep. Also in line with the previous demonstrations that PRC2 has no effect on H3-K27 monomethylation (Cao and Zhang 2004; Pasini et al. 2004), we found that DZNep did not inhibit monomethylation of H3-K27. DZNep treatment also resulted in the loss of another repressive histone mark, H4-K20 trimethylation (Fig. 2B). Thus, the effect of DZNep on H3-K27 methylation was selective but not specific.

To understand the kinetics of the changes in EZH2 and H3-K27 methylation following DZNep treatment we performed a time-course analysis (Fig. 2C). Our data showed that DZNep induced the down-regulation of EZH2 as early as $2 \mathrm{~h}$ after treatment, which was followed by the inhibition of $\mathrm{H} 3-\mathrm{K} 27 \mathrm{me} 3$ at later time points.
B

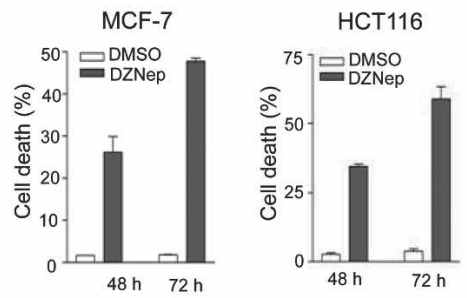

$\mathrm{D}$

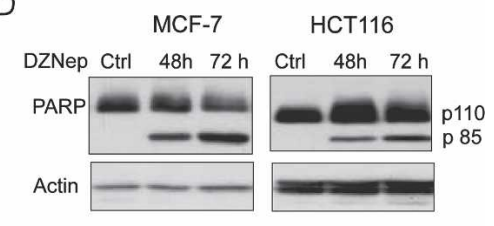

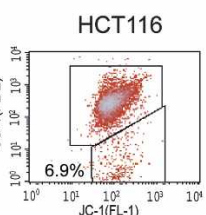

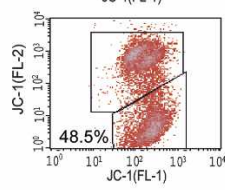

$\mathrm{E}$

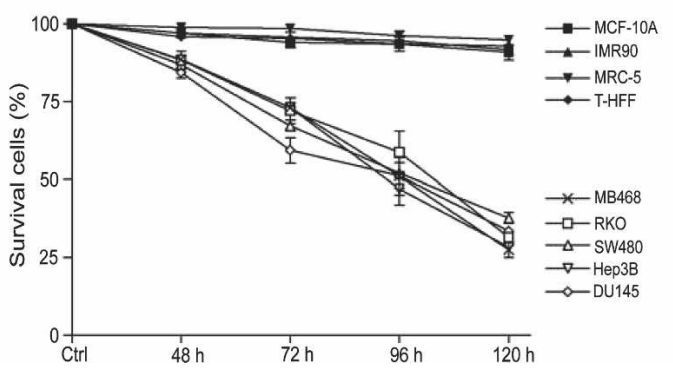

H3-K9me3 and total H3 levels, on the contrary, remained unchanged throughout the time course of DZNep treatment. These changes occurred prior to the induction of apoptosis and thus they are not likely to be the consequence of apoptotic response.

To investigate whether the reduction of the PRC2 proteins is due to the reduced expression of PRC2 mRNAs, we performed RT-PCR analysis. Figure 2D shows that the mRNA levels of each of the PRC2 proteins remained unchanged after DZNep treatment, indicating that the decrease in PRC2 components is a result of a post-transcriptional mechanism. It is known that PRC2 complex is subjected to proteosome-mediated degradation (Pasini et al. 2004). To determine if the DZNep-induced depletion of the PRC2 complex is caused by protein degradation, we treated MCF-7 cells with DZNep in the presence or absence of three different proteosome inhibitors (MG132, LLNL, and MG115). As shown in Figure 2E, treatment with each proteosome inhibitor at least in part prevented the down-regulation of EZH2 and SUZ12 protein levels in response to DZNep. These results demonstrated that DZNep depleted the PRC2 proteins through increased protein degradation.

We next explored whether the decrease in the PRC2 
A

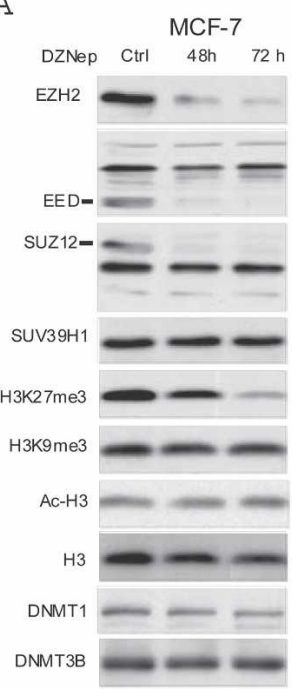

D

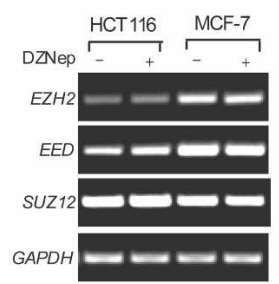

E

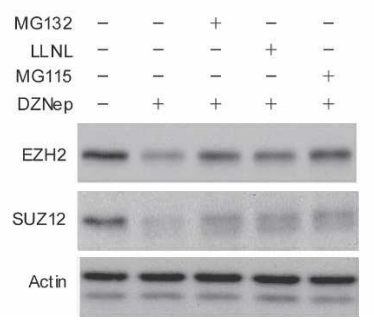

B

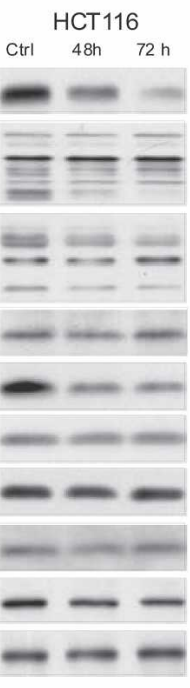

C
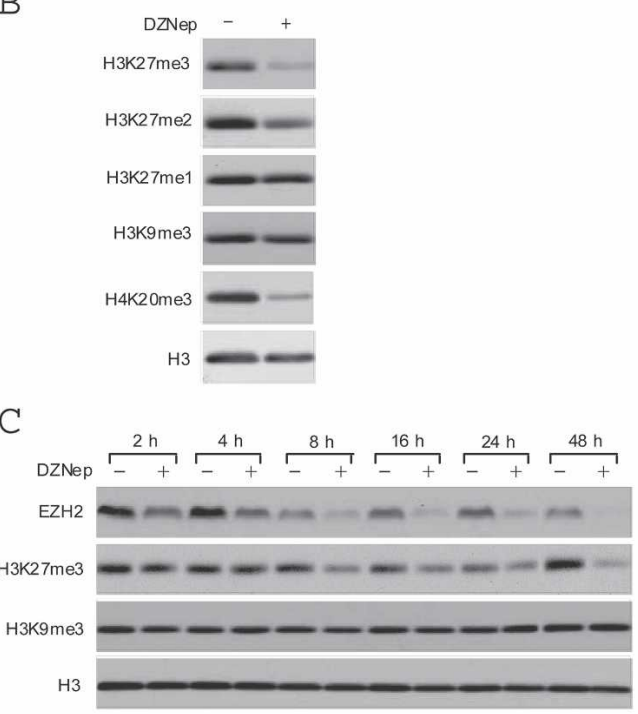

G
F
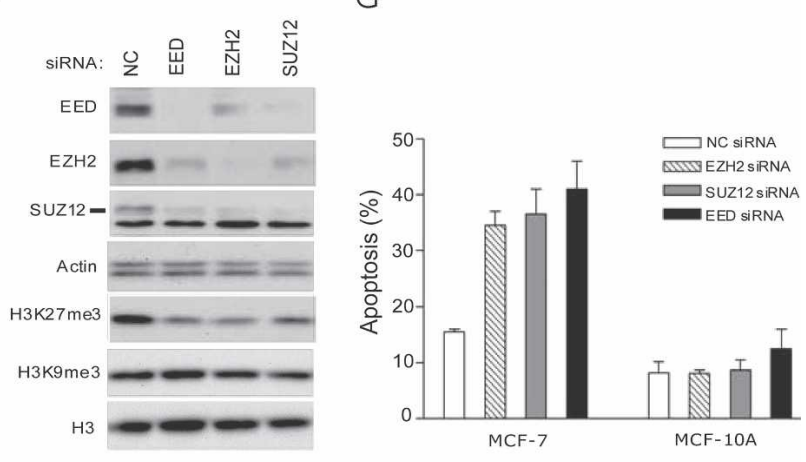

Figure 2. Effects of DZNep on PRC2 proteins and histone methylations. (A) MCF-7 and HCT116 cells were treated with $5 \mu M$ DZNep for 48 and $72 \mathrm{~h}$ and cells were harvested for Western blot analysis using antibodies detecting the indicated proteins. $(B)$ MCF-7 cells were treated with DZNep for $48 \mathrm{~h}$ and the levels of indicated histone methylations were examined by Western blot analysis. (C) MCF-7 cells were treated with DZNep for the indicated times and cells were harvested for Western blot analysis of the indicated proteins. $(D)$ MCF-7 and HCT116 cells were treated as in A and total RNA was isolated for RT-PCR analysis of EZH2, EED, and SUZ12 mRNA levels. (E) MCF-7 cells were treated with DZNep for $18 \mathrm{~h}$, followed by the addition of proteosome inhibitors MG132 (5 $\mu$ M), LLNL (50 $\mu \mathrm{M})$, or MG115 $(20 \mu \mathrm{M})$ for $8 \mathrm{~h}$. Cells were harvested for Western blot analysis of EZH2 and SUZ12. $(F)$ MCF-7 cells were treated with siRNA targeting EZH2, EED, or SUZ12 individually. After $72 \mathrm{~h}$, cells were harvested and the levels of PRC2 proteins and H3-K27me3, $\mathrm{H} 3-\mathrm{K} 9 \mathrm{me} 3$, and total $\mathrm{H} 3$ were examined by Western blot analysis as indicated. (G) MCF-7 and MCF-10A cells were treated as in $F$ and cell death was measured by PI staining and FACS analysis. Data represent \pm SD from three independent experiments.

complex is responsible for DZNep-induced apoptosis. The expression level of EZH2 mRNA in MCF-7 cells was fivefold higher than that in MCF-10A cells (data not shown), and thus we used these two cell lines to test whether knockdown of PRC2 proteins (EZH2, EED, and SUZ12) would result in apoptosis in these cells. Western blot analysis of small interfering RNA (siRNA)-treated MCF-7 cells for $72 \mathrm{~h}$ confirmed the knockdown efficiency (Fig. 2F). Notably, the knockdown of each of the PRC2 proteins resulted in the down-regulation of the other two components, a result in agreement with the previous finding that the protein level of each PRC2 component is dependent on the presence of the other members of the complex (Pasini et al. 2004). As an expected result of PRC2 knockdown, histone H3-K27 trimethylation was markedly reduced, while the H3-K9 trimethylation and total $\mathrm{H} 3$ levels remained unchanged (Fig. 2F). Notably, PRC2 siRNA treatments resulted in significant apoptosis in MCF-7 cells compared with MCF-7 cells receiving a control siRNA, whereas PRC2 siRNA did not induce apoptosis in MCF-10A cells (Fig. 2G). These findings indicate that DZNep-induced apo- 
ptosis in MCF-7 cells resulted, at least in part, from the decrease in the PRC2 complex.

\section{Identification of PRC2-repressed genes reactivated by DZNep in breast cancer cells}

As our data suggest that the induction of apoptosis by DZNep in cancer cells may be due to the release of PRC2-mediated transcriptional repression, we next sought to determine a common set of target genes repressed by $\mathrm{PRC} 2 / \mathrm{H} 3 \mathrm{~K} 27 \mathrm{me} 3$, which can be reactivated upon DZNep treatment. We focused these studies on breast cancer cells since EZH2 expression levels in MCF-7 cells are fivefold higher compared with MCF-10A cells (data not shown). Using the same siRNA strategy as above, we first analyzed the changes in global gene expression after individual knockdown of the three core components of PRC2 (EZH2, SUZ12, and EED) using Illumina $24 \mathrm{~K}$ Gene Expression BeadChips. Subsequent data analysis revealed 708, 684, and 572 genes up-regulated more than twofold after EZH2, EED, and SUZ12 siRNA treatment, respectively. In total, there were 1402 genes whose expression was increased upon knockdown of at least one out of three PRC2 proteins. To be inclusive, we considered all 1402 genes to be potential PRC2 target genes in subsequent analyses.

We next performed an array analysis to identify genes up-regulated by DZNep. Treatment of MCF-7 cells with DZNep for $72 \mathrm{~h}$ led to the up-regulation of 751 genes twofold or greater. Comparing this DZNep-inducible gene list with the 1402 candidate PRC2 target gene list, we identified an overlap of 140 genes $(p<0.0001)$ (Fig. 3A). We consider these 140 genes to be PRC2-repressed targets that can be transcriptionally reactivated by DZNep. The remaining 611 genes induced by DZNep but apparently unaffected by PRC2 knockdown may represent targets repressed by other MTases, as DZNep would also inhibit their function.

Since the inhibition of the PRC2 complex induces apoptosis in MCF-7 cells but not in MCF-10A cells, we reasoned that some of the PRC2 target genes in MCF-7 cells might be differentially expressed between cancerous and noncancerous cells and thus respond to DZNep treatment differently. Thus, to identify genes specifically repressed by PRC2 in breast cancer cells, we generated expression data from the noncancerous MCF-10A cells that were either untreated or treated with DZNep (Supplementary Table S1). As illustrated in Figure 3B, gene clustering revealed that, of the 140 genes sensitive to DZNep and PRC2 knockdown in MCF-7 cells, 44 had at least twofold lower expression in MCF-7 cells compared with MCF-10A cells. The remainder of the putative PRC2 target genes was expressed either at similar levels between the two cell types or at higher levels in MCF-7 cells (Fig. 3B). Subsequent RT-PCR analysis on a random subset of 10 of these genes confirmed their silenced or repressed expression in MCF-7 cells compared with MCF-10A cells, which was restored upon DZNep or PRC2 siRNAs treatment (Fig. 3C). While DZNep treatment resulted in an average fourfold induction of these 44 genes in MCF-7 cells, no obvious change (less than onefold) was observed in MCF-10A cells (Fig. 3D). Thus, we have uncovered a set of 44 genes specifically repressed by PRC2 in cancerous as opposed to normal breast epithelial cells that can be reactivated upon DZNep treatment. Within this list may be the genes responsible for the apoptotic response of DZNep on MCF-7 cells.

Gene Ontology (GO) analysis revealed that these genes were remarkably enriched for their roles in growth inhibition or apoptosis, as seen in TGFBI and IGFBP3 (Fig. $3 E)$. Thus, these genes are likely to be putative tumor suppressors of the malignant phenotype epigenetically silenced or repressed by PRC2 in breast cancers. Preferential reactivation of PRC2-repressed growth control genes in cancer cells relative to the normal cells might explain the cancer selectivity of DZNep.

To determine whether our findings in cancer cell lines are representative of primary breast tumors, we queried a gene expression data set of 28 primary breast tumor samples and nine normal breast tissues for the expression of our 44 genes specifically repressed by PRC2 in MCF-7 cells. Of these 44 genes, 34 unique probes were found to be present in this Affymetrix array data set. Together with EZH2, SUZ12, and EED, this gene set clearly separated the tumor and normal samples by using unsupervised cluster analysis (Fig. 3F). A subset of 17 genes (Cluster I) showed lower expression in breast tumors relative to the normal breast tissues, which, as expected, was correlated with the higher EZH2 and SUZ12 expression in breast tumors. These data strongly suggest that this subset of PRC2 targets is the clinically relevant one whose expression is repressed in primary human breast cancers.

\section{Effect of DZNep on PRC2 and RNA polymerase II (RNA Pol II) occupancy on target promoters}

We next used chromatin immunoprecipitation (ChIP) to determine whether PRC2 binds to the target gene promoters described above, and whether this binding is affected by DZNep treatment. To gain further mechanistic insight, we also analyzed the promoter occupancy for RNA Pol II, as RNA Pol II and PRC2 are known to occupy gene promoters in a mutually exclusive manner (Lee et al. 2006; Vire et al. 2006). We reasoned that the depletion of PRC2 by DZNep would result in increased RNA Pol II recruitment to the PRC2 target gene promoters. We examined eight candidate PRC2 target gene promoters using ChIP PCR primers designed within the core promoter region (Fig. 4A); 95\% of PRC2-binding sites are known to localize to within $1 \mathrm{~kb}$ of the transcription start site of a gene with or without a CpG island (Lee et al. 2006). As shown by ChIP analysis performed using SUZ12 or RNA Pol II antibodies, untreated MCF-7 cells displayed strong binding of SUZ12 to all eight gene promoters, whereas only background or minimal binding was detected in nonspecific IgG or RNA Pol II pull-down samples (Fig. 4B). Forty-eight hours after treatment with DZNep, SUZ12 binding was markedly 
A

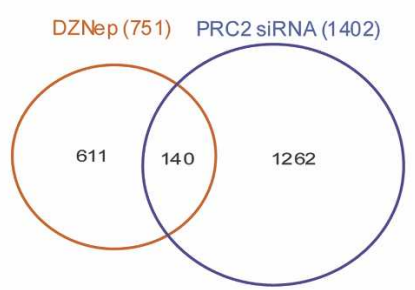

B

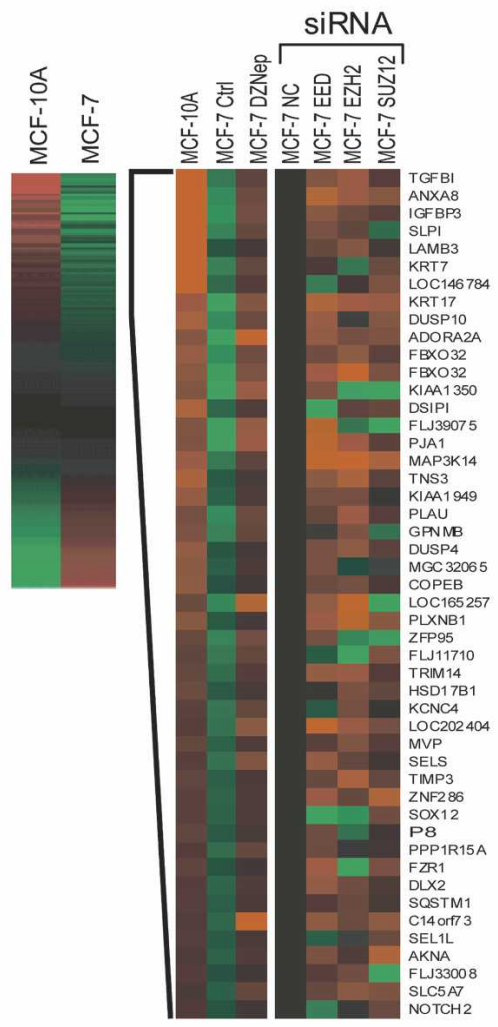

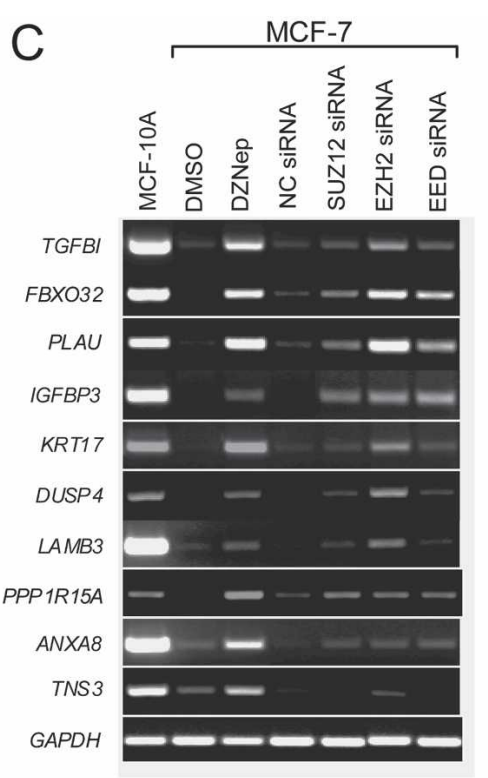

E

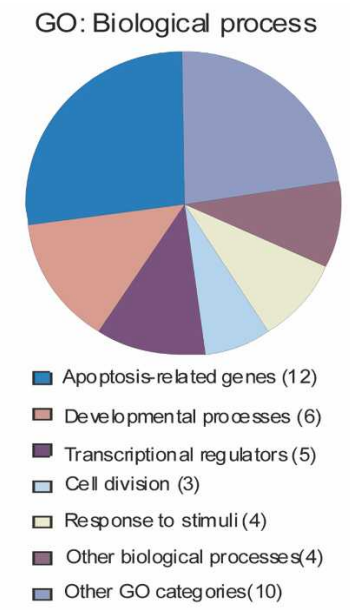

\section{$\mathrm{F}$}

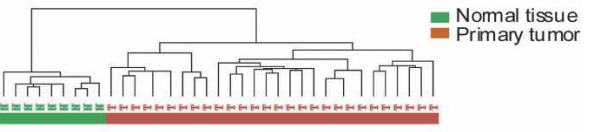

D

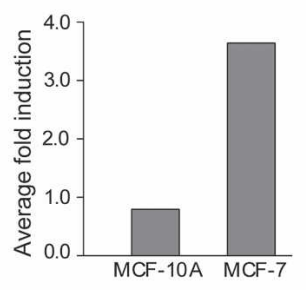

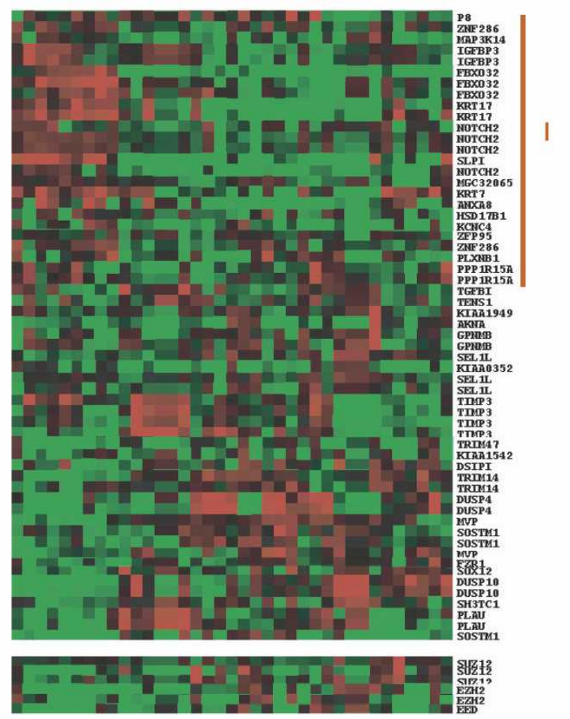

Figure 3. Identification of DZNep-activated PRC2 target genes in breast cancer cells. $(A)$ Vent diagram showing the overlapping genes up-regulated in DNZep-treated and PRC2 siRNA-treated MCF-7 cells. Cells were treated with DZNep or individual EZH2, EED, or SUZ12 siRNA for $72 \mathrm{~h}$ and gene expression was performed using the Illumina 24K BeadArray system. Genes (751) were up-regulated for twofold or greater upon DZNep treatment and 1402 genes were up-regulated for twofold or greater in at least one out three PRC2 knockdown conditions. (B, left panel) Cluster diagram showing the PRC2 targets expressed differentially in MCF-7 and MCF-10A cells. Genes are rank-ordered by levels of high expression (red) and low expression (green) in MCF-7 cells relative to MCF-10A cells. Clustering of 44 target genes selectively repressed in MCF-7 cells and their reactivation by DZNep or siRNAs targeting individual PRC2 proteins is shown in the right panel. (C) RT-PCR validation of 10 PRC2 target genes. (D) Averaged fold of induction of 44 PRC2 targets by DZNep in MCF-10A versus MCF-7 cells. (E) GO assignments of the gene functions. $(F)$ Hierarchical clustering of PRC2 target genes in primary breast tumors $(\mathrm{T})$ and normal breast tissues $(\mathrm{N})$. Cluster I represents the PRC2 target genes whose expression is down-regulated in primary tumors compared with the normal tissues.

reduced, and Pol II binding increased on all eight promoters. Taken together with the re-expression of these genes after depletion of PRC2 by DZNep, these findings confirmed that PRC2 binding to these gene promoters is required for their transcriptional repression. Disruption of PRC2 proteins by DZNep reduced this binding, resulting in the increased recruitment of RNA Pol II and transcriptional activation of these PRC2 target genes.
Reactivation of PRC2-repressed targets by DZNep is not attributed to DNA demethylation

It has been shown that EZH2 can directly control DNA methylation through the recruitment of DNMT to certain PRC2 target gene promoters (Vire et al. 2006). This raises the possibility that DZNep-mediated reactivation of PRC2 target genes might be the result of DNA de- 
A

Figure 4. DZNep treatment removes the binding of PRC2 to their target genes and increases the binding of RNA Pol II. $(A)$ Schematic representations of $5^{\prime}$-flanking regions of candidate $\mathrm{PRC} 2$ target genes. Arrows point to the transcription start sites. Vertical bars indicate CpG sites. Regions analyzed by PCR are shown by black bars at the bottom. ChIP primers are located on the core promoter regions of analyzed genes. (B) ChIPs show that DZNep treatment reduces the binding of SUZ12 to the promoter of target genes but increases binding of RNA Pol II to these gene promoters. Nonspecific IgG was used as a control. Input represents the genomic DNA.

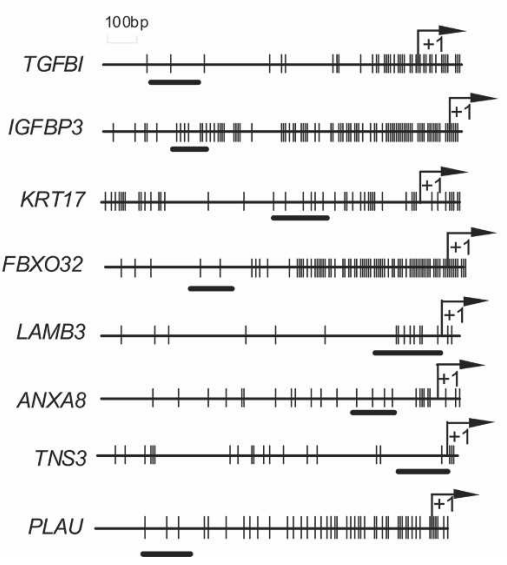

B

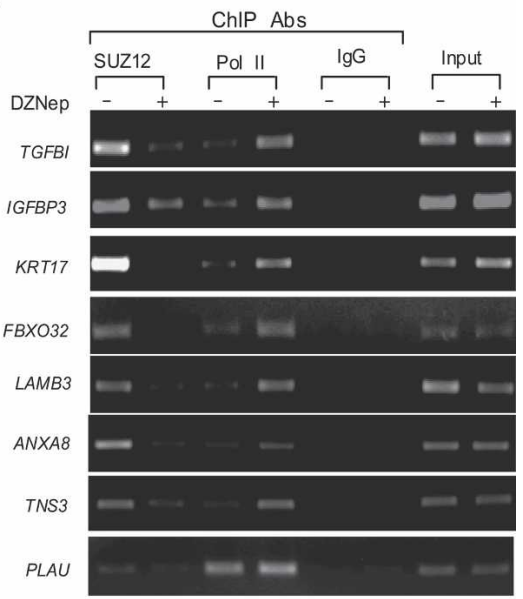

methylation. If so, the treatment of MCF-7 cells with the DNA demethylating agent $5-\mathrm{AzaC}$ or in combination with the HDACI trichostatin A (TSA) should also be able to reactivate these genes. To test this hypothesis, we used the same BeadArray expression analysis on MCF-7 cells treated with either 5-AzaC alone or with TSA and compared this with the previously profiled DZNeptreated MCF-7 cells. The 140 genes we previously identified as PRC2-repressed and DZNep-activated in MCF-7 cells (see above) did not show significant activation upon either 5-AzaC or 5-AzaC/TSA treatment as compared with DZNep (Fig. 5A, left panel). However, as a positive control for 5-AzaC and 5-AzaC/TSA treatment, p18INK4C expression showed a strong induction (threefold and 18-fold, respectively) (Fig. 5A, right panel). Thirteen of the 140 PRC2 target genes $(\sim 10 \%)$ were increased threefold or greater upon combined treatment of 5-AzaC and TSA (see Supplementary Table S2), suggesting that only a small portion of DZNep-induced PRC2 target genes can be induced through DNA methylation. However, this did not appear to be the case for the remaining PRC2 targets since the same treatment did not induce their expression.

To obtain direct evidence to support our conclusion, we performed a quantitative DNA methylation analysis using the SEQUENOM MassARRAY System that uses MALDI-TOF mass spectrometry (MS) analysis of basespecifically cleaved amplification products (Ehrich et al. 2005). We analyzed methylation patterns of 21 PRC2 target genes in MCF-7 cells, comparing the methylation patterns between untreated cells, cells treated with DZNep, and cells treated with 5-AzaC (see Supplementary Table S3). The results revealed that nearly $50 \%$ of these PRC2 target genes were unmethylated in examined amplicons. Thus, it is unlikely that DNA methylation is responsible for the silenced expression of all PRC2 targets. Figure 5B shows the methylation patterns of six representative $\mathrm{PRC} 2$ target gene promoters that are either unmethylated (TGFBI, KRT17, and PPP1R15A) or hypermethylated (FBXO32, KRT7, and IGFBP3) and their changes in expression levels following the above treatments, as measured by real time RT-PCR analysis (right side). For unmethylated genes, it is obvious that their activation by DZNep is independent of DNA methylation status. For FBXO32 and KRT7 that appeared to be hypermethylated in many CpG sites, we found that both DZNep and 5-AzaC induced demethylation of some CpG sites, suggesting that DZNep treatment indeed can cause DNA demethylation in these genes. However, while treatment with 5 -AzaC or 5 -AzaC plus TSA failed to induce expression of these genes, DZNep, in contrast, strongly activated their expression (Fig. 5B). Thus, DNA demethylation alone might not be a major contributing factor in DZNep-induced gene reactivation. However, we do not exclude the possibility that DNA demethylation events in certain PRC2 target gene promoters are functionally important for achieving optimal gene activation, perhaps in coordination with changes in histone methylations to produce a synergistic effect.

\section{Identification of PRC2 target genes associated with cellular sensitivity to DZNep}

To determine whether our DZNep observations in MCF-7 cells were consistent with other breast cancer cell lines, we treated MDA-MB-468, SK-BR-3, MDA-MB231, T47D, and BT-549 cell lines with DZNep. The apoptotic response in a time-course analysis revealed that these cell lines exhibited a varied sensitivity to DZNep. Similar to MCF-7 cells, MDA-MB-468, SK-BR-3, and T47D cells were highly susceptible to DZNep-induced cell death. In contrast, the response of the MDAMB-231 and BT-549 cell lines was similar to the noncancerous MCF-10A cells; that is, they were resistant to DZNep-induced cell death (Fig. 6A).

The cellular sensitivity to DZNep may be a result of differential gene activation between these cell lines, so we were next interested in identifying such differences between DZNep sensitivity and resistance. We generated similar BeadArray gene expression data for these 
A
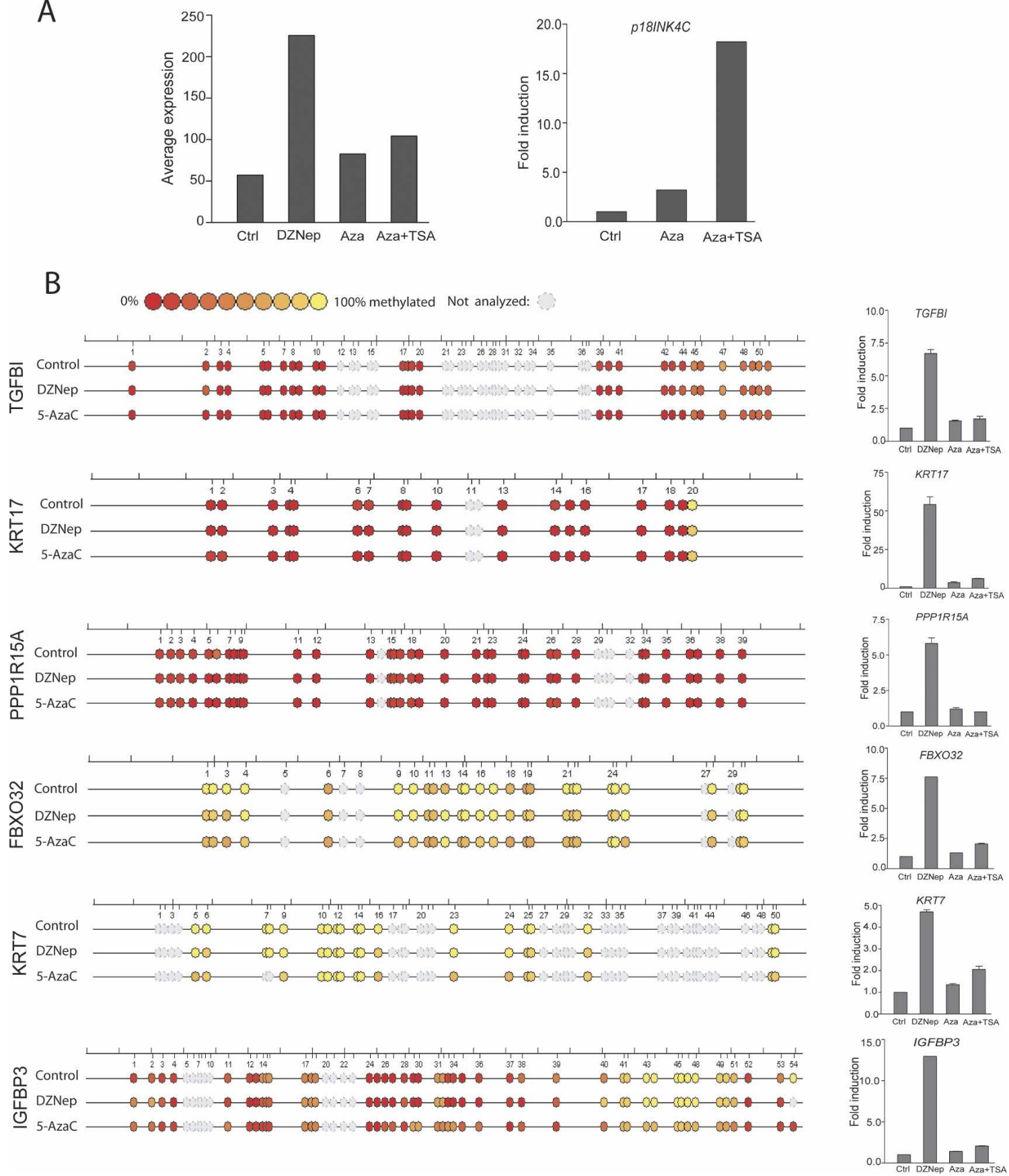

Figure 5. Effects of DZNep and 5-AzaC on PRC2 target gene expression and DNA methylation status. $(A)$ MCF-7 cells were untreated or treated with DZNep, 5-AzaC, or 5-AzaC plus TSA, and RNA was isolated for gene array expression analysis. The averaged expression levels of 140 PRC2 targets are shown on the left. Inductions of p18INK4C expression by 5-AzaC or 5-AzaC plus TSA as a positive control are shown on the right. (B) Methylation status of six representative PRC2 target gene promoters in MCF-7 cells either untreated or treated with DZNep or 5-AzaC. Each color-coded ball represents one CpG site. Red indicates low level of methylation and yellow indicates high level of methylation. Gray indicates the missing data. The corresponding changes in gene expression upon treatment with DZNep, 5-AzaC, or 5-AzaC plus TSA were evaluated by quantitative RT-PCR and the results are shown on the right. The detailed information about the genomic locations of each amplicon and the percentage of methylation at each CpG site in each of the amplicons can be found in Supplementary Table S3.

additional breast cancer cell lines before and after DZNep treatment (see Supplementary Table S4). Unsupervised cluster analysis of the previously defined 44 cancer-specific PRC2-repressed genes sensitive to DZNep treatment (see above) clearly separates the cell lines that are sensitive to DZNep-induced cell death 
Figure 6. Identification of PRC2 target genes associated with DZNep sensitivity. (A) Indicated cell lines were treated with 5 $\mu \mathrm{M}$ DZNep for 72,96 , and $120 \mathrm{~h}$ and cell death was measured by FACS analysis. The data presented are the average of three independent experiments. (B) Unsupervised clustering of 44 PRC2 targets in indicated breast cancer cell lines. Genes highlighted in green are highly expressed in resistant cell lines relative to sensitive cell lines. $(C)$ Cluster program showing genes up-regulated by DZNep in at least three sensitive cell lines. $(D)$ Indicated cell lines were treated with or without DZNep for $72 \mathrm{~h}$ and cells were harvested to examine the mRNA levels of FBXO32, LAMB3, $P L A U$, and PPP1R15A by quantitative real-time RT-PCR analysis. Shown are the folds of induction after 72-h treatment of DZNep. (E) Indicated breast cancer cell lines were treated with DZNep for $48 \mathrm{~h}$ and EZH2 and SUZ12 protein levels were determined by Western blotting.
A

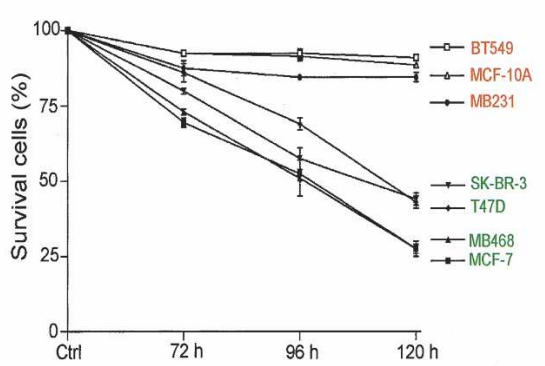

C

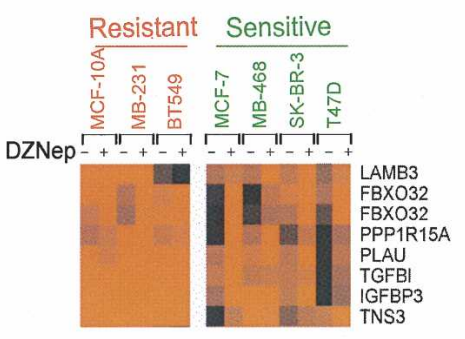

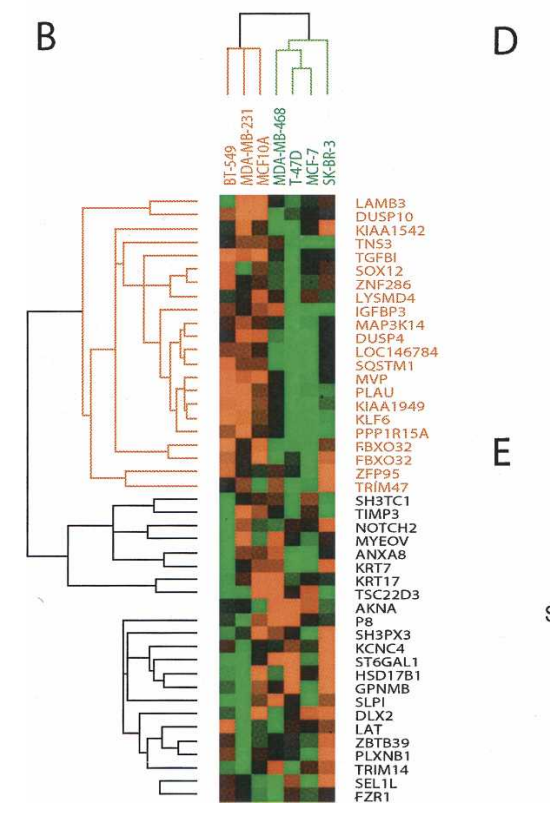

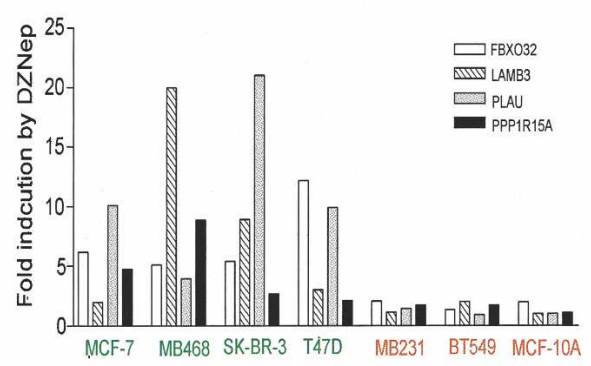

$E$

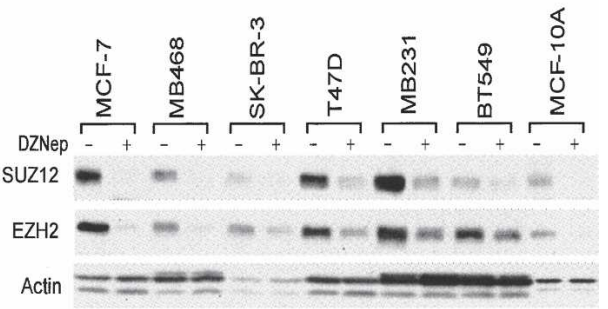

from those that are not, solely based on expression in untreated cells (Fig. 6B). The differences in expression among a subset of 22 genes were responsible for this separation; these genes were expressed at a much higher level in the DZNep-resistant cell lines (Fig. 6B). Upon DZNep treatment, four of these 22 genes (FBXO32, $L A M B 3, P L A U$, and PPP1R15A) were found to be upregulated in all four DZNep-sensitive cell lines. Also, three additional genes (TGFBI, IGFBP3, TNS3) were induced in three of four sensitive cell lines. In the resistant cell lines, these genes (excluding LAMB3 in BT-549 cells) were already highly expressed and did not undergo marked further induction after DZNep treatment (Fig. 6C). Real-time RT-PCR analysis of FBXO32, LAMB3, $P L A U$, and PPP1R15A confirmed the array data (Fig. 6D). Therefore, the suppressed expression of these seven genes and the extent of their induction by DZNep appeared to be associated with the breast cancer cell sensitivity to DZNep-induced cell death.

The resistant cell phenotype is not due to the inability of DZNep to deplete the PRC2 complex, as depletion was evident in all these cell lines (Fig. 6E). In addition, the 22 genes expressed in the resistant cell lines but repressed in the sensitive cell lines did not undergo further increases upon DZNep treatment. This indicates that, although present in these resistant cells, PRC2 is not functional to repress their transcription, perhaps due to a

lack of additional factors (e.g., DNMT and HDAC) required for the epigenetic control of these genes.

Reactivation of FBXO32 plays a crucial role in mediating DZNep-induced apoptosis

In order to investigate the functional significance of the seven genes we identified above as potential mediators of the DZNep death response, we used siRNA technology to limit their up-regulation upon DZNep treatment of MCF-7 cells. Dharmacon SMARTpool siRNAs were introduced into the cells prior to treatment with DZNep, and apoptosis was measured after $3 \mathrm{~d}$. Of the seven genes, the knockdown of FBXO32 was the only one that significantly reduced the apoptotic response to DZNep (Fig. 7A). To further validate the effect of FBXO32 siRNA and to exclude the possibility of off-target effects of the RNA interference (RNAi) we synthesized a different $F B X O 32$ siRNA, which gave a virtually identical result (Fig. 7B). To further substantiate this finding, we created cell lines derived from MCF-7 that constitutively expressed a short hairpin RNA (shRNA) targeting $F B X O 32$ or a nonspecific control shRNA. Two independent, stable clonal lines expressing the FBXO32 shRNA had greatly reduced magnitudes of $F B X O 32$ reactivation upon treatment with DZNep (Fig. 7C). Accordingly, 
A

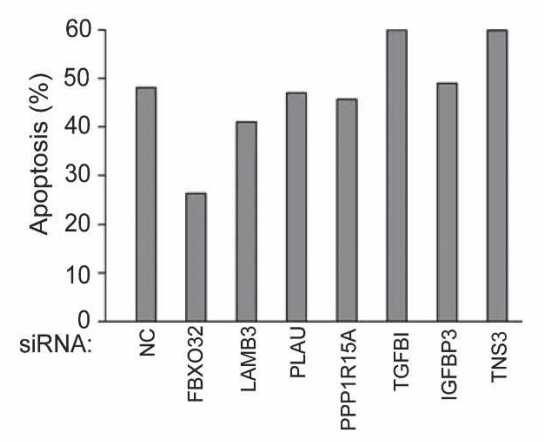

C

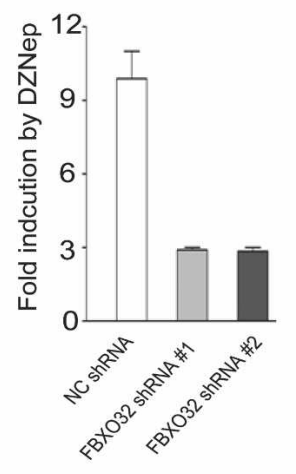

E
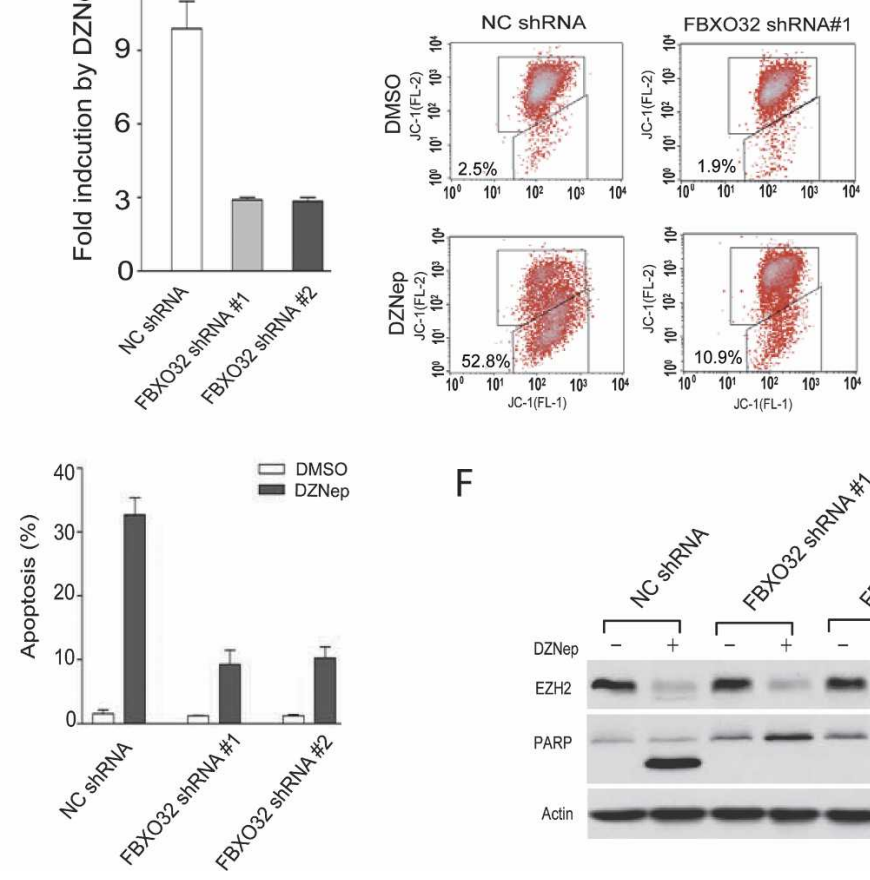

$\mathrm{F}$

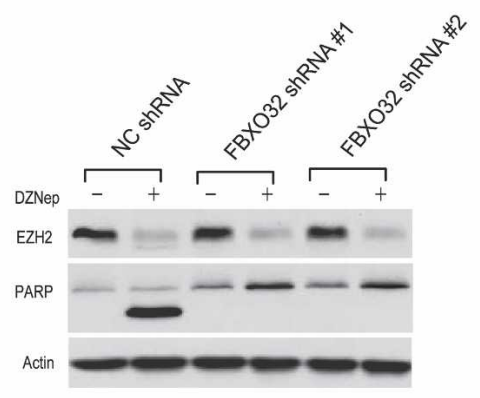

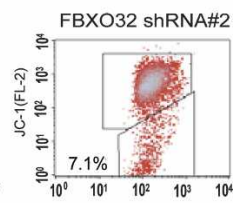
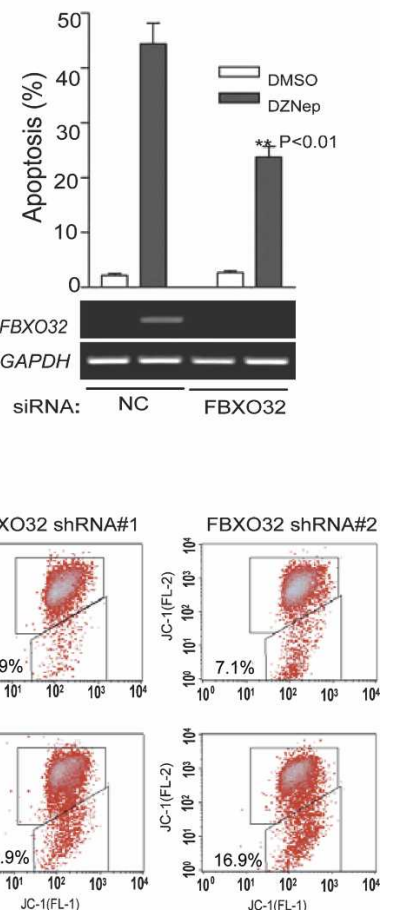

Figure 7. FBXO32 is functionally required for DZNep-induced apoptosis. $(A)$ Each of indicated Dharmacon SMARTpool siRNA was transfected into MCF-7 cells for $24 \mathrm{~h}$, followed by $5 \mu \mathrm{M}$ DZNep treatment for $72 \mathrm{~h}$. Apoptosis was measured by FACS analysis. Only FBXO32 siRNA was capable of reducing DZNep-induced apoptosis. (B) A FBXO32 siRNA targeting a different region of $F B X O 32$ also inhibited DNZep-induced apoptosis in MCF-7 cells compared with a nontargeting siRNA control (NC). Shown are the results of three independent experiments. The knockdown of FBXO32 mRNA expression is shown by RT-PCR at the bottom. $(C)$ The levels of FBXO32 mRNA in two MCF-7 stable clones expressing FBXO32 shRNA or nontargeting control shRNA (NC shRNA) were determined by real-time RT-PCR. The graph shows the fold of induction of FBXO32 mRNA following DZNep treatment in each stable clone as indicated. (D) MCF-7 cells expressing FBXO32 shRNA or NC shRNA were treated with DZNep for $72 \mathrm{~h}$ and the cell death was measured by PI staining and FACS analysis. $(E)$ Cells were treated as in $D$ and JC-1 staining was performed. $(F)$ Cells were treated as in $D$ and Western blot analysis was performed to detect the PARP cleavage.
DZNep-induced apoptosis in these cells was strongly inhibited compared with the shRNA control MCF-7 cell line. This decreased apoptosis was measured by three independent means: by fluorescence-activated cell sorting (FACS) analysis measuring either sub-G1 population or MTP (Fig. 7D,E), and by PARP cleavage using Western blot analysis (Fig. 7F). These experiments strongly indicate that the reactivation of FBXO32 in MCF-7 cells is required for efficient apoptosis induction by DZNep. Although removal of other apoptosis-associated PRC2 targets such as TGFBI and IGFBP3 alone did not seem to cause significant inhibition of DZNep-induced apoptosis in MCF-7 cells, their coordinated and collective activation might still contribute to the DZNep-induced apoptotic process under different cellular contexts. Our data suggest that the level of expression of FBXO32 in breast cancer cells, together with other PRC2 targets, as well as the extent to be induced by DZNep appear to be an important determinant of DZNep-induced apoptosis in breast cancer cells.

\section{Discussion}

Loss of tumor suppressors through epigenetic repression is a hallmark of human cancer. Strategies to reverse epigenetic gene silencing might therefore be useful in cancer therapy. In this study we describe the effect of a AdoHcy hydrolase inhibitor, DZNep, on chromatin remodeling as well as its ability to preferentially induce apoptosis in cancer cells. We provide evidence that DZNep-induced apoptosis is at least partly due to the down-regulation of PRC2 complex. Using this DZNep compound along with RNAi, gene expression analysis, and ChIP, we uncovered a set of genes that are suppressed in human breast cancer cells through PRC2-mediated repression but are reactivated upon treatment with DZNep. We further identify the key PRC2 target genes whose reactivation is associated with DZNep-induced apoptosis.

As an AdoHcy hydrolase inhibitor, DZNep interferes with AdoMet-AdoHcy metabolism and can cause re- 
duced methylation reaction indirectly (Glazer et al. 1986). Unlike DNA hypomethylating agents such as 5'AzaC and zebularine that deplete DNMTs (Velicescu et al. 2002; Cheng et al. 2004), this compound appears to have no effect on DNMTs but induces efficient depletion of the PRC2 proteins and the associated histone-H3-K27 methylation. Interestingly, DZNep appears to have no effect on Suv39h1 and the associated H3-K9 methylation, although the reason for this remains to be determined. The depletion of PRC2 proteins after DZNep treatment is not achieved via transcriptional inhibition since DZNep treatment did not affect their mRNA levels. Instead, it is at least in part mediated through proteosomal degradation since proteosome inhibitors can restore PRC2 protein expression. Unlike 5-AzaC and zebularine that deplete DNMTs by incorporating and thus trapping them to the substituted DNA /Cheng et al. 2004), DZNep is not phosphorylated and does not get incorporated into DNA (Glazer et al. 1986; Tseng et al. 1989|. Thus it seems highly unlikely that DZNep depletes PRC2 proteins through a similar mechanism. It is unclear how all three PRC2 proteins are degraded upon DZNep treatment. However, it is known that downregulation of one PRC2 component can result in the degradation of the other two in the complex since the integrity of this complex depends on the existence of each component (Bracken et al. 2003; Pasini et al. 2004; Montgomery et al. 2005). Thus, it is possible that inhibition of AdoHcy hydrolase by DZNep might affect one of the core PRC2 components, resulting in the instability of the whole complex and subsequent inhibition of H3-K27 methylation.

Since AdoMet-dependent methylation is involved in many cellular processes (Chiang et al. 1996), targeting AdoHcy hydrolase by DZNep is expected to inhibit the activities of multiple MTases. Indeed, we found that DZNep treatment also inhibited methylation of another repressive histone mark, H4-K20 methylation, suggesting that other histone MTases could also be susceptible to inhibition by DZNep. This might explain why only 140 out of 751 DZNep-activated genes appeared to be regulated by EZH2. The induction of the rest of the genes could be the result of inhibition of MTases other than EZH2, and they might also be involved in DZNep-induced apoptosis. Nevertheless, the immediate effects of DZNep on PRC2 and H3-K27 methylation, as well as target gene activation for apoptosis, demonstrate that DZNep-induced apoptosis is, at least in part, related to its ability to inhibit the PRC2 pathway. Until now, DZNep has been explored for antiviral treatment (De Clercq et al. 1989) and has been shown to have minimal toxicity in vivo (Bray et al. 2000). Regardless of the exact mechanism, its intriguing apoptotic activity in cancer cells but not in normal cells, together with the important cancer epigenetic pathway it affects, makes it a promising drug candidate for anti-cancer treatment.

Guided by pharmacological, genomic, and functional analysis, we identified a group of PRC2 targets that appeared to be repressed in both breast cancer cells and primary breast tumors. Further analysis of breast cancer cell lines showing resistant or sensitive response to DZNep led to identification of a set of PRC2 target genes that are associated with cellular sensitivity to DZNep. Among those are TGFBI, IGFBP3, and PPPIR15A, which are previously known to be involved in apoptosis or growth control. In particular, we functionally validated a novel cell death regulator, FBXO32, whose reactivation appeared to be required for the efficient apoptosis induction by DZNep. FBXO32 encodes MAFbx (muscle atrophy F-box protein, also called atrogin-1), which belongs to the F-box protein family as part of the SCF ubiquitin protein E3 ligase complex. The role of FBXO32 in negatively regulating cell survival has been implicated in a previous finding showing that its expression could be inhibited by the prosurvival PI3K/Akt pathway (Stitt et al. 2004). Importantly, we confirmed the repressed expression of FBXO32 in primary breast tumors relative to the normal tissues. Recently, two other members of the F-box family, FBXW7 and FBX4, have been shown to function as tumor suppressors by targeting multiple oncogenic proteins such as Myc, cyclin E, or cyclin D1 for ubiquitin-dependent protein degradation (Welcker et al. 2004; Minella and Clurman 2005; Fujii et al. 2006; Lin et al. 2006). Therefore, FBXO32 seems to be a PRC2-repressed target gene with a potential tumor suppressor function.

Although individual knockdown of other apoptosisassociated PRC2 targets seems to be insufficient to inhibit DZNep-induced apoptosis, their contribution to this apoptotic process in a collective or coordinated manner, depending on the cellular context, should not be ruled out. This small set of genes might serve as a surrogate marker for predicting the response of DZNep to breast cancer cells and guide the selection of the subset of breast cancer patients for PRC2-targeted therapy in the future. Our study suggests that the loss of expression of growth control PRC2 target genes in some cancer cells might create an "epigenetic addiction," in which cancer cells depend on their silenced expression for a growth advantage. Restored expression of these genes will result in growth inhibition or apoptosis, pointing to a novel therapeutic approach leading to the preferential killing of tumor versus nontumor cells. Furthermore, given the role of PRC2 and histone methylation in stem cell maintenance (Sparmann and van Lohuizen 2006), it is conceivable that inhibiting PRC2 and associated histone methylation might also have implications in targeting cancer stem cells.

In addition to catalyzing H3-K27 methylation, PRC2 also recruits DNMT to methylated cytosines at $\mathrm{CpG}$ sites in the promoter regions of certain PRC2 target genes (Vire et al. 2006). Although DZNep presumably can inhibit multiple methylation reactions, we found that its ability to activate the PRC2-repressed genes might not be the result of inhibition of DNA methylation in general. This conclusion was supported by using both pharmacological and DNA methylation analyses. Only $\sim 10 \%$ of PRC 2 target genes can be induced by the DNMT inhibitor $5^{\prime}$-AzaC or 5'-AzaC plus HDAC inhibitor TSA, suggesting that PRC2-linked DNA hypermeth- 
ylation appears to be operative only in a proportion of the PRC2 targets. In addition, many of the PRC2 targets we examined in MCF-7 cells were found to be hypomethylated in CpGsites we examined. For the small numbers of highly methylated PRC2 targets, DZNep indeed induced their demethylation in some CpG sites, but this demethylation event alone is insufficient for the robust gene activation induced by DZNep because demethylation of the same CpG sites by $5^{\prime}$-AzaC or $5^{\prime}$-AzaC plus TSA did not activate their expression. Therefore, the effects of DZNep on chromatin are distinguishable from other chromatin remodeling agents such as DNMT and HDAC inhibitors, and DZNep appears to be the first compound capable of reactivating gene expression by modulating PRC2 and associated histone methylations. Moreover, the unique effects of DZNep on chromatin remodeling make its use in combination with other chromatin remodeling agents an attractive approach to synergistically restoring abnormally silenced genes in cancer.

Taken together, our work underscores the importance of PRC2-mediated gene repression in maintaining survival of cancer cells. Our identification of AdoHcy hydrolase inhibitor DZNep, which can reverse PRC2 and histone methylation-mediated gene silencing and effectively induce cancer cell death, opens the therapeutic potential of inhibiting this epigenetic regulator. We anticipate the therapeutic index of PRC2 and histone methylation-directed therapies to be inherently high since normal cells appear to have a less active repressor function of the PRC2 complex compared with tumor cells.

\section{Materials and methods}

Cells and drug treatment

Cell lines used in this study were purchased from the American Type Culture Collection. Cells were maintained in DMEM supplemented with $10 \%$ fetal bovine serum, $2 \mathrm{mM}$ L-glutamine, and $5000 \mathrm{U} / \mathrm{mL}$ penicillin/streptomycin and maintained at $37^{\circ} \mathrm{C}$ with $5 \% \mathrm{CO}_{2}$. For drug treatment, cells were seeded the day before the drug treatment. Cells were treated with $5 \mu \mathrm{M}$ DZNep or $2 \mu$ M 5-AzaC (Sigma) for $72 \mathrm{~h}$, and TSA (Sigma) at 100 $\mathrm{nM}$ for $24 \mathrm{~h}$. For 5-AzaC treatment, the medium was replaced with freshly added 5-AzaC for every $24 \mathrm{~h}$. For cotreatment of cells with 5-AzaC and TSA, 5-AzaC was added for $48 \mathrm{~h}$, followed by TSA for $24 \mathrm{~h}$.

\section{$R N A i$}

Specific siRNA oligos targeting EZH2, SUZ12, and EED mRNAs were described previously (Cao and Zhang 2004; Kirmizis et al. 2004; Bracken et al. 2006). The SMARTpool siRNA reagents of selected PRC2 targets and the nontargeting control were purchased from Dharmacon. A separate FBXO32 siRNA targeting the sequence 5'-GTCACATCCTTTCCTGGAA-3' was obtained from Sigma-Proligo. Cells were transfected with $50 \mathrm{nM}$ final concentration of siRNA duplexes using Lipofectamine 2000 (Invitrogen) following the manufacturer's instructions. To generate FBXO32 shRNA stable cells, the FBXO32 siRNA sequence or a nontargeting control siRNA sequence was cloned into the pSIREN-RetroQ retroviral expression vector (BD Bioscience) according to the manufacturer's instruction. Virally infected cells were selected in a medium containing $2 \mu \mathrm{g} / \mathrm{mL}$ puromycin, and individual drug-resistant clones were collected, pooled, and expanded.

\section{Immunoblot analysis}

Cells were scraped, collected, and lysed in RIPA buffer as described previously (Kho et al. 2004). To release histones from chromatin, cell lysates were further sonicated for $15 \mathrm{sec}$ using a XL2000 Microson Ultrasonic Processor (Misonix). Equal amounts of protein $(50 \mu \mathrm{g})$ were separated on SDS-polyacrylamide gels and transferred to PVDF membranes. The blots were probed with antibodies against EED (07-368), SUZ12 (07-379), SUV39H1 (07-550), trimethylated H3-K27 (07-449), trimethylated H3-K9 (07-442), monomethylated H3-K27 (07-448), dimethylated H3-K27 (07-452), and Acetyl-Histone H3 (06-599), which were purchased from Upstate Biotechnology. Trimethylated H4-K20 (ab9053) was from Abcam. EZH2 (AC22) and Histone $\mathrm{H} 3(3 \mathrm{H} 1)$ were from Cell Signaling. Antibodies against DNMT1 and DNMT3B were purchased from Alexis Biochemicals.

\section{Flow cytometric analysis}

Cells were harvested and fixed in $70 \%$ ethanol. Fixed cells were stained with PI $(50 \mu \mathrm{g} / \mathrm{mL})$ after treatment with RNase (100 $\mu \mathrm{g} / \mathrm{mL})$. The stained cells were analyzed for DNA content by FACS in a FACSCalibur (Becton Dickinson Instrument). Cell cycle fractions were quantified using the CellQuest software (Becton Dickinson). To measure MTP, cells were stained with JC-1, according to the manufacturer's instructions (BD Bioscience), and cells positive for JC-1 detection were measured using CellQuest software (BD Bioscience).

\section{Microarray analysis and quantitative real-time PCR}

Total RNA was isolated from cell lines using Trizol (Invitrogen) and purified with the RNAeasy Mini Kit (Qiagen). Reverse transcription was performed using an RNA Amplification kit (Ambion). The microarray hybridization was performed using the Illumina Gene Expression BeadChip (Illumina) and data analysis was performed using GeneSpring software from Agilent Technologies. Gene expression of normal and primary breast tumor samples was performed using Affymetrix U133A GeneChips (Affymetrix) following the manufacturer's instructions. Gene expression data from individual arrays were normalized by median centering and average linkage hierarchical clustering was done using Cluster and Treeview software (http://rana.lbl.gov/EisenSoftware.htm). Quantitative real-time PCR was performed on a PRISM 7900 Sequence Detection System (Applied Biosystems) using TaqMan probes (Applied Biosystems). Samples were normalized to the levels of $18 \mathrm{~S}$ ribosomal RNA.

\section{ChIP assays}

ChIP assays were performed as described previously (Zhao et al. 2005). MCF-7 cells were treated with or without DZNep (5 $\mu \mathrm{M})$ for $48 \mathrm{~h}$. Precleared chromatin from $2 \times 10^{7}$ MCF7 cells were immunoprecipitated with anti-SUZ12 (07-379, Upstate Biotechnology), anti-RNA polymerase II (sc-899, Santa Cruz Biotechnology), and a nonspecific IgG (sc-2027, Santa Cruz Biotechnology). The ChIP-precipitated DNA and input DNA were subjected to PCR analysis. The PCR primers are listed in Supplementary Table S5.

\section{DNA methylation analysis}

Customer service for DNA methylation analysis was performed by Sequenom, Inc., using the MassARRAY system as previously described (Ehrich et al. 2005). 


\section{Acknowledgments}

We thank Dr. Paul Robson for critically reviewing the manuscript. This work was supported by the Agency for Science, Technology, and Research of Singapore. We thank the National Cancer Institute (USA) for providing the compound library and DZNep.

\section{References}

Baylin, S.B. and Ohm, J.E. 2006. Epigenetic gene silencing in cancer-A mechanism for early oncogenic pathway addiction? Nat. Rev. Cancer 6: 107-116.

Beisel, C., Imhof, A., Greene, J., Kremmer, E., and Sauer, F. 2002. Histone methylation by the Drosophila epigenetic transcriptional regulator Ash1. Nature 419: 857-862.

Bernstein, B.E., Mikkelsen, T.S., Xie, X., Kamal, M., Huebert, D.J., Cuff, J., Fry, B., Meissner, A., Wernig, M., Plath, K., et al. 2006. A bivalent chromatin structure marks key developmental genes in embryonic stem cells. Cell 125: 315-326.

Boyer, L.A., Plath, K., Zeitlinger, J., Brambrink, T., Medeiros, L.A., Lee, T.I., Levine, S.S., Wernig, M., Tajonar, A., Ray, M.K., et al. 2006. Polycomb complexes repress developmental regulators in murine embryonic stem cells. Nature 441: 349-353.

Bracken, A.P., Pasini, D., Capra, M., Prosperini, E., Colli, E., and Helin, K. 2003. EZH2 is downstream of the pRB-E2F pathway, essential for proliferation and amplified in cancer. EMBO T. 22: 5323-5335.

Bracken, A.P., Dietrich, N., Pasini, D., Hansen, K.H., and Helin, K. 2006. Genome-wide mapping of Polycomb target genes unravels their roles in cell fate transitions. Genes \& Dev. 20: 1123-1136.

Bray, M., Driscoll, J., and Huggins, J.W. 2000. Treatment of lethal Ebola virus infection in mice with a single dose of an S-adenosyl-L-homocysteine hydrolase inhibitor. Antiviral Res. 45: 135-147.

Cao, R. and Zhang, Y. 2004. SUZ12 is required for both the histone methyltransferase activity and the silencing function of the EED-EZH2 complex. Mol. Cell 15: 57-67.

Cao, R., Wang, L., Wang, H., Xia, L., Erdjument-Bromage, H., Tempst, P., Jones, R.S., and Zhang, Y. 2002. Role of histone H3 lysine 27 methylation in Polycomb-group silencing. Science 298: 1039-1043.

Cheng, J.C., Yoo, C.B., Weisenberger, D.J., Chuang, J., Wozniak, C., Liang, G., Marquez, V.E., Greer, S., Orntoft, T.F., Thykjaer, T., et al. 2004. Preferential response of cancer cells to zebularine. Cancer Cell 6: 151-158.

Chiang, P.K. 1981. Conversion of 3T3-L1 fibroblasts to fat cells by an inhibitor of methylation: Effect of 3-deazaadenosine. Science 211: 1164-1166.

Chiang, P.K. and Cantoni, G.L. 1979. Perturbation of biochemical transmethylations by 3-deazaadenosine in vivo. Biochem. Pharmacol. 28: 1897-1902.

Chiang, P.K., Burbelo, P.D., Brugh, S.A., Gordon, R.K., Fukuda, K., and Yamada, Y. 1992. Activation of collagen IV gene expression in F9 teratocarcinoma cells by 3-deazaadenosine analogs. Indirect inhibitors of methylation. J. Biol. Chem. 267: 4988-4991.

Chiang, P.K., Gordon, R.K., Tal, J., Zeng, G.C., Doctor, B.P., Pardhasaradhi, K., and McCann, P.P. 1996. S-Adenosylmethionine and methylation. FASEB J. 10: 471-480.

De Clercq, E., Cools, M., Balzarini, J., Marquez, V.E., Borcherding, D.R., Borchardt, R.T., Drach, J.C., Kitaoka, S., and Konno, T. 1989. Broad-spectrum antiviral activities of neplanocin A, 3-deazaneplanocin A, and their $5^{\prime}$-nor derivatives.
Antimicrob. Agents Chemother. 33: 1291-1297.

Ehrich, M., Nelson, M.R., Stanssens, P., Zabeau, M., Liloglou, T., Xinarianos, G., Cantor, C.R., Field, J.K., and van den Boom, D. 2005. Quantitative high-throughput analysis of DNA methylation patterns by base-specific cleavage and mass spectrometry. Proc. Nat1. Acad. Sci. 102: 15785-15790.

Feinberg, A.P. and Tycko, B. 2004. The history of cancer epigenetics. Nat. Rev. Cancer 4: 143-153.

Fraga, M.F., Ballestar, E., Villar-Garea, A., Boix-Chornet, M., Espada, J., Schotta, G., Bonaldi, T., Haydon, C., Ropero, S., Petrie, K., et al. 2005. Loss of acetylation at Lys16 and trimethylation at Lys20 of histone $\mathrm{H} 4$ is a common hallmark of human cancer. Nat. Genet. 37: 391-400.

Fujii, Y., Yada, M., Nishiyama, M., Kamura, T., Takahashi, H., Tsunematsu, R., Susaki, E., Nakagawa, T., Matsumoto, A., and Nakayama, K.I. 2006. Fbxw7 contributes to tumor suppression by targeting multiple proteins for ubiquitin-dependent degradation. Cancer Sci. 97: 729-736.

Gil, J., Bernard, D., and Peters, G. 2005. Role of polycomb group proteins in stem cell self-renewal and cancer. DNA Cell Biol. 24: $117-125$.

Glazer, R.I., Hartman, K.D., Knode, M.C., Richard, M.M., Chiang, P.K., Tseng, C.K., and Marquez, V.E. 1986. 3-Deazaneplanocin: A new and potent inhibitor of S-adenosylhomocysteine hydrolase and its effects on human promyelocytic leukemia cell line HL-60. Biochem. Biophys. Res. Commun. 135: 688-694.

Holden, C. 2006. Development. Gene-suppressing proteins reveal secrets of stem cells. Science 312: 349 .

Jones, P.A. and Baylin, S.B. 2002. The fundamental role of epigenetic events in cancer. Nat. Rev. Genet. 3: 415-428.

Kalantry, S., Mills, K.C., Yee, D., Otte, A.P., Panning, B., and Magnuson, T. 2006. The Polycomb group protein Eed protects the inactive X-chromosome from differentiation-induced reactivation. Nat. Cell Biol. 8: 195-202.

Kamminga, L.M., Bystrykh, L.V., de Boer, A., Houwer, S., Douma, J., Weersing, E., Dontje, B., and de Haan, G. 2006. The Polycomb group gene Ezh2 prevents hematopoietic stem cell exhaustion. Blood 107: 2170-2179.

Kennison, J.A. 1995. The Polycomb and trithorax group proteins of Drosophila: Trans-regulators of homeotic gene function. Annu. Rev. Genet. 29: 289-303.

Kennison, J.A. 2004. Introduction to Trx-G and Pc-G genes. Methods Enzymol. 377: 61-70.

Kho, P.S., Wang, Z., Zhuang, L., Li, Y., Chew, J.L., Ng, H.H., Liu, E.T., and Yu, Q. 2004. p53-regulated transcriptional program associated with genotoxic stress-induced apoptosis. J. Biol. Chem. 279: 21183-21192.

Kirmizis, A., Bartley, S.M., and Farnham, P.J. 2003. Identification of the polycomb group protein $\mathrm{SU}(\mathrm{Z}) 12$ as a potential molecular target for human cancer therapy. Mol. Cancer Ther. 2: 113-121.

Kirmizis, A., Bartley, S.M., Kuzmichev, A., Margueron, R., Reinberg, D., Green, R., and Farnham, P.J. 2004. Silencing of human polycomb target genes is associated with methylation of histone H3 Lys 27. Genes \& Dev. 18: 1592-1605.

Kleer, C.G., Cao, Q., Varambally, S., Shen, R., Ota, I., Tomlins, S.A., Ghosh, D., Sewalt, R.G., Otte, A.P., Hayes, D.F., et al. 2003. EZH2 is a marker of aggressive breast cancer and promotes neoplastic transformation of breast epithelial cells. Proc. Natl. Acad. Sci. 100: 11606-11611.

Kuzmichev, A., Margueron, R., Vaquero, A., Preissner, T.S., Scher, M., Kirmizis, A., Ouyang, X., Brockdorff, N., AbateShen, C., Farnham, P., et al. 2005. Composition and histone substrates of polycomb repressive group complexes change during cellular differentiation. Proc. Natl. Acad. Sci. 102: 
$1859-1864$

Lee, T.I., Jenner, R.G., Boyer, L.A., Guenther, M.G., Levine, S.S., Kumar, R.M., Chevalier, B., Johnstone, S.E., Cole, M.F., Isono, K., et al. 2006. Control of developmental regulators by Polycomb in human embryonic stem cells. Cell 125: 301313.

Lehnertz, B., Ueda, Y., Derijck, A.A., Braunschweig, U., PerezBurgos, L., Kubicek, S., Chen, T., Li, E., Jenuwein, T., and Peters, A.H. 2003. Suv39h-mediated histone H3 lysine 9 methylation directs DNA methylation to major satellite repeats at pericentric heterochromatin. Curr. Biol. 13: 11921200.

Levine, S.S., King, I.F., and Kingston, R.E. 2004. Division of labor in polycomb group repression. Trends Biochem. Sci. 29: 478-485.

Lin, D.I., Barbash, O., Kumar, K.G., Weber, J.D., Harper, J.W., Klein-Szanto, A.J., Rustgi, A., Fuchs, S.Y., and Diehl, J.A. 2006. Phosphorylation-dependent ubiquitination of cyclin D1 by the SCF(FBX4- $\alpha$ B crystallin) complex. Mol. Cell 24: 355-366.

Liu, S., Wolfe, M.S., and Borchardt, R.T. 1992. Rational approaches to the design of antiviral agents based on S-adenosyl-L-homocysteine hydrolase as a molecular target. Antiviral Res. 19: 247-265.

Lund, A.H. and van Lohuizen, M. 2004. Polycomb complexes and silencing mechanisms. Curr. Opin. Cell Biol. 16: 239246.

Marks, P.A., Richon, V.M., Miller, T., and Kelly, W.K. 2004. Histone deacetylase inhibitors. Adv. Cancer Res. 91: 137168.

Milne, T.A., Briggs, S.D., Brock, H.W., Martin, M.E., Gibbs, D., Allis, C.D., and Hess, J.L. 2002. MLL targets SET domain methyltransferase activity to Hox gene promoters. Mol. Cell 10: 1107-1117.

Minella, A.C. and Clurman, B.E. 2005. Mechanisms of tumor suppression by the SCF(Fbw7). Cell Cycle 4: 1356-1359.

Montgomery, N.D., Yee, D., Chen, A., Kalantry, S., Chamberlain, S.J., Otte, A.P., and Magnuson, T. 2005. The murine polycomb group protein Eed is required for global histone $\mathrm{H} 3$ lysine-27 methylation. Curr. Biol. 15: 942-947.

Muller, J., Hart, C.M., Francis, N.J., Vargas, M.L., Sengupta, A., Wild, B., Miller, E.L., O'Connor, M.B., Kingston, R.E., and Simon, J.A. 2002. Histone methyltransferase activity of a Drosophila Polycomb group repressor complex. Cell 111: 197-208.

Nakamura, T., Mori, T., Tada, S., Krajewski, W., Rozovskaia, T., Wassell, R., Dubois, G., Mazo, A., Croce, C.M., and Canaani, E. 2002. ALL-1 is a histone methyltransferase that assembles a supercomplex of proteins involved in transcriptional regulation. Mol. Cell 10: 1119-1128.

Nebbioso, A., Clarke, N., Voltz, E., Germain, E., Ambrosino, C., Bontempo, P., Alvarez, R., Schiavone, E.M., Ferrara, F., Bresciani, F., et al. 2005. Tumor-selective action of HDAC inhibitors involves TRAIL induction in acute myeloid leukemia cells. Nat. Med. 11: 77-84.

Pasini, D., Bracken, A.P., Jensen, M.R., Lazzerini Denchi, E., and Helin, K. 2004. Suz12 is essential for mouse development and for EZH2 histone methyltransferase activity. EMBO J. 23: 4061-4071.

Peters, A.H., O'Carroll, D., Scherthan, H., Mechtler, K., Sauer, S., Schofer, C., Weipoltshammer, K., Pagani, M., Lachner, M., Kohlmaier, A., et al. 2001. Loss of the Suv39h histone methyltransferases impairs mammalian heterochromatin and genome stability. Cell 107: 323-337.

Pirrotta, V. 1999. Polycomb silencing and the maintenance of stable chromatin states. Results Probl. Cell Differ. 25: 205-
228

Pirrotta, V. 2006. Polycomb silencing mechanisms and genomic programming. Ernst Schering Res. Found. Workshop (57): 97-113.

Razin, A., Levine, A., Kafri, T., Agostini, S., Gomi, T., and Cantoni, G.L. 1988. Relationship between transient DNA hypomethylation and erythroid differentiation of murine erythroleukemia cells. Proc. Nat1. Acad. Sci. 85: 9003-9006.

Rea, S., Eisenhaber, F., O'Carroll, D., Strahl, B.D., Sun, Z.W., Schmid, M., Opravil, S., Mechtler, K., Ponting, C.P., Allis, C.D., et al. 2000. Regulation of chromatin structure by sitespecific histone H3 methyltransferases. Nature 406: 593599.

Rhodes, D.R., Sanda, M.G., Otte, A.P., Chinnaiyan, A.M., and Rubin, M.A. 2003. Multiplex biomarker approach for determining risk of prostate-specific antigen-defined recurrence of prostate cancer. J. Natl. Cancer Inst. 95: 661-668.

Sellers, W.R. and Loda, M. 2002. The EZH2 polycomb transcriptional repressor-A marker or mover of metastatic prostate cancer? Cancer Cell 2: 349-350.

Sparmann, A. and van Lohuizen, M. 2006. Polycomb silencers control cell fate, development and cancer. Nat. Rev. Cancer 6: $846-856$

Stitt, T.N., Drujan, D., Clarke, B.A., Panaro, F., Timofeyva, Y., Kline, W.O., Gonzalez, M., Yancopoulos, G.D., and Glass, D.J. 2004. The IGF-1/PI3K/Akt pathway prevents expression of muscle atrophy-induced ubiquitin ligases by inhibiting FOXO transcription factors. Mol. Cell 14: 395-403.

Tan, J., Zhuang, L., Jiang, X., Yang, K.K., Karuturi, K.M., and Yu, Q. 2006. Apoptosis signal-regulating kinase 1 is a direct target of E2F1 and contributes to histone deacetylase inhibitorinduced apoptosis through positive feedback regulation of E2F1 apoptotic activity. J. Biol. Chem. 281: 10508-10515.

Tseng, C.K., Marquez, V.E., Fuller, R.W., Goldstein, B.M., Haines, D.R., McPherson, H., Parsons, J.L., Shannon, W.M., Arnett, G., Hollingshead, M., et al. 1989. Synthesis of 3-deazaneplanocin A, a powerful inhibitor of S-adenosylhomocysteine hydrolase with potent and selective in vitro and in vivo antiviral activities. J. Med. Chem. 32: 1442-1446.

van der Vlag, J. and Otte, A.P. 1999. Transcriptional repression mediated by the human polycomb-group protein EED involves histone deacetylation. Nat. Genet. 23: 474-478.

Varambally, S., Dhanasekaran, S.M., Zhou, M., Barrette, T.R., Kumar-Sinha, C., Sanda, M.G., Ghosh, D., Pienta, K.J., Sewalt, R.G., Otte, A.P., et al. 2002. The polycomb group protein EZH2 is involved in progression of prostate cancer. Nature 419: 624-629.

Velicescu, M., Weisenberger, D.J., Gonzales, F.A., Tsai, Y.C., Nguyen, C.T., and Jones, P.A. 2002. Cell division is required for de novo methylation of CpG islands in bladder cancer cells. Cancer Res. 62: 2378-2384.

Vire, E., Brenner, C., Deplus, R., Blanchon, L., Fraga, M., Didelot, C., Morey, L., Van Eynde, A., Bernard, D., Vanderwinden, J.M., et al. 2006. The Polycomb group protein EZH2 directly controls DNA methylation. Nature 439: 871-874.

Welcker, M., Orian, A., Grim, J.E., Eisenman, R.N., and Clurman, B.E. 2004. A nucleolar isoform of the Fbw7 ubiquitin ligase regulates c-Myc and cell size. Curr. Biol. 14: 1852 1857.

Yoo, C.B. and Jones, P.A. 2006. Epigenetic therapy of cancer: Past, present and future. Nat. Rev. Drug Discov. 5: 37-50.

Zhao, Y., Tan, J., Zhuang, L., Jiang, X., Liu, E.T., and Yu, Q. 2005. Inhibitors of histone deacetylases target the Rb-E2F1 pathway for apoptosis induction through activation of proapoptotic protein Bim. Proc. Natl. Acad. Sci. 102: 1609016095. 


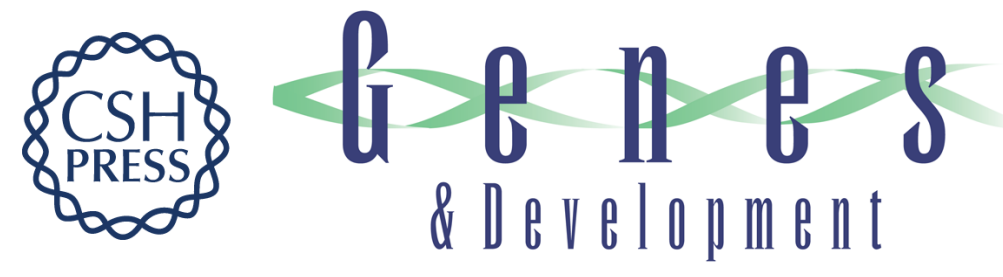

\section{Pharmacologic disruption of Polycomb-repressive complex 2-mediated gene repression selectively induces apoptosis in cancer cells}

Jing Tan, Xiaojing Yang, Li Zhuang, et al.

Genes Dev. 2007, 21: originally published online April 16, 2007

Access the most recent version at doi:10.1101/gad.1524107

Supplemental Material

References

License

Email Alerting

Service
http://genesdev.cshlp.org/content/suppl/2007/04/16/gad.1524107.DC1

This article cites 64 articles, 18 of which can be accessed free at: http://genesdev.cshlp.org/content/21/9/1050.full.html\#ref-list-1

Receive free email alerts when new articles cite this article - sign up in the box at the top right corner of the article or click here.

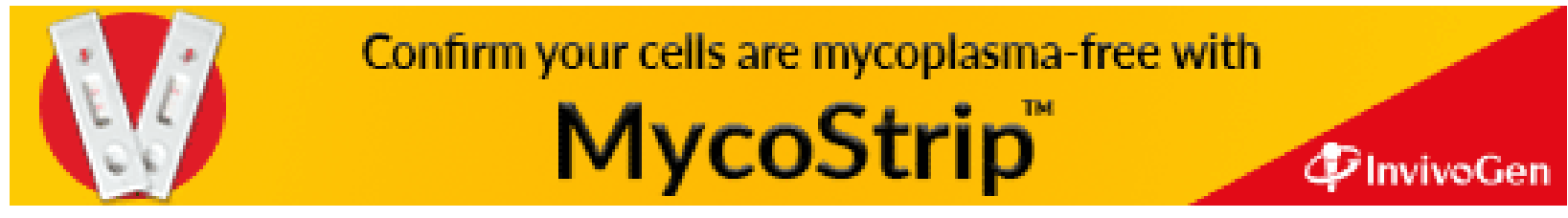

